\title{
Nacionalismo e Aprendizagem no Programa de Águas Profundas da Petrobras
}

\author{
André Tosi Furtado \\ Departamento de Política Científica e Tecnológica / Instituto de Geociências / UNICAMP \\ Adriana Gomes Freitas
}

Faculdade de Engenharia Mecânica / UNICAMP

Recebido em 2/7/2003 Aprovado em 22/3/2004

\section{Resumo}

O presente trabalho avalia os impactos econômicos resultantes de diversas formas de aprendizado que derivaram da execução de projetos tecnológicos nacionalistas. Esses projetos visavam o desenvolvimento e o domínio local de tecnologias estratégicas para o País. Toma-se como exemplo o programa de capacitação tecnológica em sistemas de produção para águas profundas da Petrobras, o Procap 1000, promovido pela Petrobras, entre 1986 e 1992. Apoiando-se em estudo anterior de avaliação dos impactos econômicos diretos e indiretos do programa (Furtado et al., 1998), foi escolhida uma amostra de sete projetos de cunho nacionalista que se caracterizam, de forma geral, por não terem sido bem-sucedidos do ponto de vista comercial. $\mathrm{O}$ argumento central deste trabalho consiste em que esses projetos, apesar do revés comercial, estiveram na origem de importantes processos de aprendizagem na empresa, os quais redundaram em significativos impactos econômicos indiretos. A descrição dos projetos mostra como a aprendizagem resultante do programa foi reaproveitada possibilitando a efetivação dos impactos econômicos. Os dados do estudo de avaliação de impactos econômicos 
da amostra de projetos do Procap 1000 revelam que os impactos econômicos superaram em mais de sete vezes os custos dos projetos. O trabalho destaca a importância da capacidade de absorção para o processo de aprendizagem. A partir de estudos de caso é proposta uma tipologia de seis formas distintas de capacidade de absorção.

Palavras-Chave | Impactos Econômicos da P\&D; Inovação; Petrobras; Capacidade de Absorção

Códigos JEL | L7, O32

\section{ABSTRACT}

This paper presents an evaluation of the economic impacts of a set of nationalistic technological projects. These projects were focused on the local technological development and mastery. The paper uses the example of Technological Capabilities in Production Systems for Deep Waters Program (Procap 1000), which was conducted by Petrobras between 1986 and 1992. Based upon a previous study of direct and indirect economic impacts of the program, a sample of seven nationalist project of the program could be chosen (Furtado et al., 1998). All the projects of this sample were characterized by an ill commercial success. The central argument of this paper is that in spite of their commercial setbacks, these projects underlie relevant learning process, which generated significant indirect economic impacts. The case studies show how learning resulting from the program was converted onto economic impacts. The figures from the study of the Procap sample indicate that economic impacts were seven times higher than the projects costs. This paper points the role of absorptive capacity to the learning process. Based on the case studies, this paper proposes a typology of six different kinds of absorptive capacities.

KeYwORDS $\quad$ R\&D Economic Impacts; Innovation; Petrobras; Absorptive Capacity JEL-Codes $\mid$ L7, O32 


\section{Introdução}

Somente a partir da segunda metade do século XX, a P\&D começou a ser considerada pelos modelos econômicos como uma atividade capaz de gerar novas riquezas. $\mathrm{O}$ arcabouço conceitual que fundamentou a medição da contribuição dessa atividade para o crescimento segue o referencial geral da teoria econômica, que representa a atividade geradora de valores econômicos como consistindo na transformação de insumos em produtos. A atividade de P\&D constitui-se num insumo que é incorporado ao processo produtivo e contribui parcialmente para o aumento da produtividade (ver, p. ex., Griliches, 1979; Mansfield, 1991). Essa visão "mecanicista" e linear do processo de inovação, em que insumos são transformados em produtos através da caixa preta da função de produção, não contribui muito para o entendimento desse processo.

A atividade de $P \& D$, além de contribuir para alcançar certos objetivos científicos e tecnológicos, implica em significativo processo de aprendizagem para a organização que a realiza. A P\&D transforma a organização que a executa de diversas maneiras: dos pontos de vista tecnológico, relacional e organizacional. Essas formas de aprendizagem podem conduzir a diversos tipos de spin-offs ${ }^{1}$ ou de impactos econômicos indiretos (tecnológicos, comerciais e organizacionais) (Bach et al., 1992).

A aprendizagem resultante da atividade de P\&D conduz a reforçar a dupla capacidade de gerar invençóes e de absorver novos conhecimentos tecnológicos externos. Esta última capacidade, analisada por Cohen e Levinthal (1989), representa a propensão da empresa ou unidade econômica em absorver o estoque de conhecimentos externos para aplicá-los em melhorias produtivas. Segundo esses autores, ela está estreitamente relacionada com o montante do esforço de P\&D realizado pela empresa:

"we argue that while $P \& D$ obviously generates innovations, it also develops the firm's ability to identify, assimilate, and exploit knowledge from the environment - what we call a firm's 'learning' or 'absorptive' capacity." (p.569)

O conceito spin-off é usado no sentido de transferência de conhecimentos de uma aplicação para outra. Pode se tratar de conhecimentos tecnológicos, organizacionais ou relacionais. 
Os desdobramentos indiretos da atividade de $\mathrm{P} \& \mathrm{D}$ foram pouco considerados na hora de se fazer a avaliação de programas e políticas de P\&D. Esse é particularmente o caso das políticas e estratégias tecnológicas desenvolvidas no Brasil nos anos 1970 e 1980. O processo de industrialização brasileiro, desde os anos 1930, foi liderado por uma elite (tecnoburocracia) que possuía uma importante inclinação para um projeto de desenvolvimento nacionalista tanto nos anos 1960 como 1970 (Schneider, 1991). Esse projeto foi, em primeiro lugar industrializante. Depois apoiou a consolidação da indústria pesada (infra-estrutura, insumos e bens de capital) liderada por empresas estatais. $\mathrm{Na}$ década de 1980, a política industrial buscou cruzar o apoio à indústria com o desenvolvimento tecnológico endógeno, o qual só ocorreria com a limitação do processo de transferência internacional de tecnologia e a entrada de empresas multinacionais em setores considerados como motores da inovação (Erber, 1988). A política que mereceu maior atenção por parte da literatura foi a da reserva de mercado para o setor de informática, a qual se iniciou com a criação da Capre em 1972 e se encerrou, pelo menos na sua versão original, em 1992. Essa política, que nunca teve um rumo muito definido, sofreu o embate político entre grupos de interesses nacionalistas (fabricantes, segmentos da tecnoestrutura, políticos, meio acadêmico) e os que defendiam uma maior abertura da economia brasileira à tecnologia e produtos externos (usuários, políticos, grupos estrangeiros) (Tapia, 1995).

A Petrobras foi um importante bastião da política de desenvolvimento nacionalista no País (Alveal Contreras, 1994). O movimento popular que levou à sua criação foi uma surpresa para o governo Vargas, e para a elite tecnoburocrática (Martins, 1976). Depois tanto a implantação do parque de refino no País como o desenvolvimento da produção de petróleo foram metas centrais que nortearam a ação da estatal. A Petrobras também serviu de instrumento para a consolidação da indústria de bens de capital sob encomenda e para a implantação da indústria petroquímica no País. Em meados da década de 1980, quando o Brasil ainda importava praticamente a metade do petróleo consumido, ocorre a descoberta de grandes reservatórios localizados em águas profundas (mais de 400 metros de lâmina d'água) que viabilizavam a autosuficiência. Porém, a tecnologia para produzir a tais profundidades não estava disponível internacionalmente. Naquele momento se consolida o projeto 
de alcançar simultaneamente as metas da auto-suficiência com o de autonomia e até mesmo liderança tecnológica. O Procap (Programa de Capacitação Tecnológica em Sistemas de Exploração em Águas Profundas) traduz esse novo estágio da estratégia nacionalista. ${ }^{2}$

A nova etapa da estratégia nacionalista pode ser considerada como um estágio mais avançado da industrialização por substituição de importações, quando se passa de um regime de proteção comercial (barreiras tarifárias, controles quantitativos e de taxa de câmbio) para outro que incorpora o protecionismo tecnológico (restrição ao capital estrangeiro, controle da transferência internacional de tecnologia) com o intuito de aumentar o domínio local e a geração endógena de tecnologia. A consagração dessa estratégia seria alcançada quando o país ou setor fosse capaz de gerar tecnologias, apoiando-se em especificidades e capacitaçôes locais, para explorar oportunidades de negócios no mercado nacional e, sobretudo, internacional. A estratégia nacionalista não se circunscreve apenas aos grandes países periféricos, mas engloba países centrais como a França e os ex-URSS e a China. Ela é plenamente coerente com a política de criação de campeões nacionais, que se tornam transnacionais, na França e nos países escandinavos.

No Brasil, as políticas de orientação nacionalista buscaram desenvolver a tecnologia localmente em setores considerados estratégicos, como os de informática, telecomunicações, armamentos, energia, etc. Essas políticas foram abandonadas com a abertura iniciada na década de 1990 por terem fracassado nos seus objetivos principais de geração endógena de tecnologia em bases competitivas.

Nosso argumento consiste em que, mesmo constituindo-se em insucessos tecnológicos e/ou comerciais, os projetos e políticas destinados a desenvolver localmente e endogenamente determinadas tecnologias, levados a cabo pela estratégia nacionalista, constituíram importantes mecanismos de aprendizagens tecnológica, organizacional e relacional, que sustentaram significativo aumento da renda dos atores concernidos.

Para ilustrar essa tese, este artigo apóia-se em um estudo de avaliação de

Segundo José Paulo Silveira, superintendente do Cenpes à época da criação do Procap 1000 "O desafio surge num momento feliz. Praticamente completamos a substituição de importações e entramos agora na fase de superação da dependência tecnológica" (Revista Brasileira de Tecnologia, jan., p.29, 1988). 
impactos econômicos do Procap 1000 (Furtado et al., 1998, 1999). ${ }^{3}$ Esse programa foi implementado pela Petrobras, de 1986 a 1992, com o propósito de lograr o domínio da tecnologia necessária para operar em lâminas d'água de até 1.000 metros de profundidade. Ele se situa no final, e talvez no apogeu, da estratégia tecnológica nacionalista associada ao período de substituição de importaçōes.

Este trabalho está organizado da seguinte forma. Primeiro, faz-se um relato de cada um dos projetos nacionalistas. Depois, apresentam-se os resultados da avaliação dos impactos econômicos dos projetos. Em seguida, à luz do estudo de caso, propõe-se uma relação das diversas formas de aprendizagem que estão relacionadas à capacidade de absorção. Com efeito, a capacidade de absorção está presente nas principais formas de aprendizagem obtidas ao longo da execução dos projetos. Finalmente, o trabalho encerra-se com uma breve conclusão.

\section{Revisão teórica}

A literatura sobre mudança técnica em países em desenvolvimento enfocou a questão de como esses países assimilam o fluxo externo de conhecimento tecnológico proveniente dos países centrais (Bell, 1984; Katz, 1981; Lall, 1982; Fransman \& King, 1984). Essa literatura tem buscado demonstrar, através da análise de casos bem-sucedidos, que a transferência internacional de tecnologia somente ocorre de forma satisfatória para o país que a assimila quando há um correspondente esforço endógeno (Kim, 1980, 1999; Dahlman \& Westphall, 1982). Ela revela que o nível de domínio tecnológico, que pode variar da simples reprodução até a inovação radical gerada endogenamente, e a etapa do processo de aprendizagem alcançada são proporcionais ao esforço local (Lall, 1992; Bell et al., 1984).

A P\&D é um tipo de esforço tecnológico que é apenas considerado para os estágios mais avançados de capacitação tecnológica, como a capacidade de inovar (Lall, 1982; Bell, 1984; Kim, 1999). Ainda assim há uma carência na compreensão de como a $P \& D$ contribui para o desenvolvimento econômico nessas etapas mais avançadas do processo de aprendizagem. Essa atividade pode

3 As características principais da metodologia de avaliação de impactos econômicos usadas neste artigo são apresentadas no Anexo.

60 Revista Brasileira de Inovação 
contribuir para gerar endogenamente inovações tecnológicas, seguindo um percurso linear que vai desde a pesquisa para o desenvolvimento e, posteriormente, à aplicação em escala industrial. Mas a P\&D pode também contribuir para aumentar a capacidade de absorção da empresa.

A forma como o conceito de capacidade de absorção tem sido explorado pela literatura está certamente relacionada ao modelo de inovação subjacente. A teoria neoclássica representa a relação positiva entre $P \& D$ e desenvolvimento econômico através de um modelo linear (Bach et al., 1998). Essa relação ocorre porque o aumento do estoque de conhecimento induz o crescimento da produtividade dos demais fatores. A maneira como essa mudança ocorre é através da aplicação desse conhecimento em invenções que são posteriormente aplicadas na atividade produtiva conduzindo ao aumento de produtividade. No que tange à capacidade de absorção, esta é percebida como uma habilidade para identificar conhecimento externo e aplicá-lo produtivamente. Entende-se a aplicação produtiva como a incorporação desse conhecimento externo em novos inventos e inovaçóes geradas pela empresa.

Essa percepção se traduz em certos estudos que visam mensurar os impactos econômicos da capacidade de absorção, que adotam claramente o modelo linear de inovação. Os indicadores de insumo considerados são os de gastos em $\mathrm{P} \& \mathrm{D}$ e os indicadores de impacto consistem em patentes, na forma de novos produtos (ver, p. ex., George et al., 2001). Essa literatura também não consegue separar os impactos oriundos da capacidade de geração de novos conhecimentos tecnológicos dos que são oriundos da capacidade de absorção (Cano \& Cano, 2001; Peris \& Mestre, 2001). Os modelos econométricos que relacionam variáveis de insumos com as de produtos também têm dificuldade para descrever como ocorre o processo de transformação (Veugelers, 1997).

A corrente evolucionista sobre o progresso técnico (Nelson \& Winter 1982; Dosi et al., 1988; Freeman, 1974; Rosenberg, 1979) coloca que as formas de relacionamento entre pesquisa e atividade econômica são múltiplas. O processo de inovação é percebido como sendo interativo e multidirecional. Não há uma etapa apenas, a da invenção, em que o aumento do conhecimento é aproveitado pelo sistema econômico. Exitem momentos distintos do processo de inovação em que o conhecimento científico é aproveitado pelo sistema econômico. Na maior parte dos campos, o que a atividade de pesquisa proporciona 
não são invenções mas conhecimentos e métodos que as empresas podem empregar numa gama muito variada de usos (Nelson, 1991). A tecnologia não requer necessariamente o avanço da ciência. Muitas vezes o avanço da ciência anda a reboque da tecnologia. O que é mais, muita inovação é feita lançando mão de conhecimento tecnológico existente.

A relação entre empresas e pesquisa acadêmica ocorre casualmente e pode incidir em diversas etapas do desenvolvimento de um novo processo, produto ou serviço. Ademais, a relação entre pesquisa e tecnologia se estabelece em duplo sentido. A nova ciência contribui para o avanço tecnológico mas a nova tecnologia também contribui para o avanço da ciência, como ilustra o caso da informática cujo espetacular avanço potencializou a pesquisa científica no campo genético.

A corrente evolucionista aporta uma visão mais completa do processo, razão pela qual a adotaremos como ponto de partida para este trabalho sobre a capacidade de absorção. A seqüência linear entre C,T\&I é apenas umas das possibilidades de inovação. $\mathrm{Na}$ realidade, esse enfoque considera que a relação entre pesquisa científica e tecnologia pode seguir vários outros caminhos. A pesquisa científica pode interferir em diversos estágios do processo de inovação. Muitas vezes é o avanço tecnológico que suscita novas perguntas que serão respondidas através da geração de novo conhecimento científico. O sentido da relação nem sempre vai da pesquisa básica para o desenvolvimento tecnológico. A existência de feedbacks entre atividades de pesquisa e produtivas da empresa é traço central do processo de inovação.

A geração de tecnologia passa a ser endogeneizada por essa corrente de análise. Ela decorre do processo de aprendizagem dos agentes econômicos que para isso devem realizar esforços específicos. A tecnologia possui uma importante dimensão tácita que não pode ser apenas reduzida ao conhecimento codificado das patentes.

O novo enfoque adota o modelo interativo (Chain-link model) como síntese analítica do processo de inovação (Kline \& Rosenberg, 1986). Esse modelo cria pelo menos cinco caminhos alternativos para a inovação, onde o linear (descoberta científica $\rightarrow$ invenção $\rightarrow$ industrialização $\rightarrow$ mercado) é apenas um deles. Esse enfoque gera importantes desdobramentos para a concepção da avaliação de P\&D. Com efeito, o modelo linear, por ser demasiadamente mecanicista, aponta para uma abordagem da avaliação em termos de 
insumo-produto, onde se quantificam os insumos, os produtos codificados e os resultados monetários diretamente relacionados a esses conhecimentos codificados. Esse modelo não é muito satisfatório porque capta apenas parcialmente os resultados da pesquisa. $\mathrm{O}$ modelo interativo aponta para o fato de que a P\&D provoca modificações muito mais amplas nos sistemas que estão envolvidos nela. Ela gera diferentes formas de interação entre os componentes desses sistemas. Freqüentemente, os caminhos da inovação possuem uma grande dose de imprevisibilidade.

A metodologia do BETA (Bureau d'Economie Théorique et Appliquée) representa uma interessante ferramenta de inspiração evolucionista, que foge ao modelo linear de inovação. Essa abordagem metodológica trata de medir os ganhos econômicos provenientes da aprendizagem lograda a partir dos esforços de P\&D. Esses ganhos são chamados de impactos indiretos.

A capacidade de absorção está estreitamente relacionada com a aprendizagem que é realizada com o projeto. Essa capacidade pode ser usada para avaliar e assimilar novos conhecimentos ou para aplicá-los produtivamente (George et al., 2001). A aplicação produtiva de conhecimentos adquiridos externamente é a dimensão que interessa ser explorada. A capacidade de absorção pode ser aproveitada em diversas etapas do processo de inovação, tanto na etapa de geração de uma invenção como em etapas posteriores quando a tecnologia já foi lançada no mercado mas ainda sofre constantes aperfeiçoamentos e melhoramentos. Nesse sentido, ela pode consistir num melhor aproveitamento de uma tecnologia transferida ou na sua melhor avaliação, contribuindo para baratear seu preço de aquisição. Essa forma de aplicação da capacidade de absorção está estreitamente relacionada com os impactos indiretos identificados através da metodologia do BETA.

\section{Os projetos nacionalistas}

A análise detalhada de sete projetos nacionalistas da amostra do estudo do Procap $1000^{4}$ permite avançar na compreensão dessa importante dimensão do processo de aprendizagem tecnológica que é a capacidade de absorção, pioneiramente modelizada por Cohen e Levinthal (1989). Existem diversas formas de

\footnotetext{
4 O estudo de avaliação do Procap 1000 (Furtado et al., 1998) avaliou uma amostra de 27 de um total de 116 projetos. Deste total, foram destacados sete projetos que intencionaram gerar conceitos ou artefatos próprios (nacionais).
} 
capacidade de absorção, as quais este trabalho empírico permitiu identificar.

Esses sete projetos tinham por objetivo o domínio local e a posterior adaptação de novos conceitos para a produção de petróleo e gás natural em águas profundas. Eram projetos pioneiros que implicavam no desenvolvimento local de soluções para serem aplicadas na fronteira tecnológica. Quase sempre tais iniciativas envolviam a engenharia básica da Petrobras, às vezes junto com empresas e universidades nacionais. Em certos casos, as empresas estrangeiras foram contratadas para repassar a tecnologia à Petrobras. Desses sete projetos, dois eram de plataformas (TLP e Vitória-Regia) e cinco de equipamentos. O nível de envolvimento dos participantes nas diversas etapas do processo de inovação variou bastante (Quadro 1).

QUADRO 1

Amostra de Projetos Nacionalistas do Procap 1000

\begin{tabular}{|c|c|c|c|c|c|}
\hline \multirow[t]{2}{*}{ Projeto } & \multicolumn{4}{|c|}{ Grau de Aplicação do Novo Conhecimento } & \multirow[t]{2}{*}{ Participação Externa } \\
\hline & Conceito Básico & Detalhamento & Protótipo & Fabricação & \\
\hline Bombeio Submarino & $x$ & $x$ & $x$ & & \\
\hline TLP & $x$ & & & & TT $\left({ }^{*}\right)$ Universidade \\
\hline ANM & $x$ & $x$ & $x$ & $x$ & $\mathrm{TT}\left({ }^{*}\right)$ \\
\hline Manifold & $x$ & $x$ & & & $\mathrm{TT}\left({ }^{*}\right)$ \\
\hline Octos 1000 & $x$ & $x$ & & & Universidade \\
\hline Vitória-Regia & $x$ & & & & $\mathrm{TT}\left({ }^{*}\right)$ \\
\hline ROR & $x$ & $x$ & $\mathrm{x}$ & $x$ & Empresa Nacional \\
\hline
\end{tabular}

(*) Transferência de Tecnologia de Empresa Estrangeira

Fonte: Pesquisa da Unicamp, 1998.

\subsection{Bombeio Submarino com Separador}

Trata-se de tecnologia com grande potencial inovador cuja promessa principal é antecipar e aumentar a produção de petróleo e gás natural em águas profundas. A Petrobras, com o intuito de se consolidar nesse novo campo tecnológico, propôs-se desenvolver um equipamento de bombeamento e separação submarina. Embora essa fosse uma tecnologia de fronteira na década de 1980,

64 Revista Brasileira de Inovação 
a Petrobras decidiu criar o seu próprio conceito (separação em poço falso com gás) a partir do início da década. Quando o Procap 1000 iniciou, essa tecnologia já havia sido patenteada pelo Cenpes (Centro de Pesquisa da Petrobras), vindo a se chamar de Petroboost. No programa a empresa planejou passá-la para a escala piloto construindo um protótipo. A confecção desse artefato foi uma excelente escola para que a equipe do projeto tirasse o conceito do papel e o aplicasse efetivamente.

A construção do protótipo do Petroboost foi um sucesso tecnológico. Os testes mostraram que ele funcionava satisfatoriamente, atendendo aos requisitos técnicos. Porém, no momento da passagem à escala industrial, esse conceito não logrou vencer a barreira da avaliação técnico-econômica. $O$ projeto, que foi conduzido de forma bastante isolada pela Petrobras, enfrentou sérias dificuldades no momento de ser transferido aos fabricantes. As empresas nacionais não conseguiram se adequar às especificações técnicas da Petrobras. As estrangeiras, em compensação, embora fossem mais capacitadas tecnicamente, não se interessaram ou apresentaram orçamentos muito caros para sua construção.

O grande ganho obtido com o projeto foi o aumento da capacidade de absorção e de negociação da Petrobras relacionada a novos conhecimentos de fronteira. Com isto a empresa logrou escapar ao lock-in da própria tecnologia do Petroboost. A estratégia desenvolvida pela empresa, a partir de então, foi sempre a de manter uma certa pluralidade tecnológica, através da participação em consórcios para o desenvolvimento de novos conceitos. De forma que a capacitação tecnológica constituída com o Petroboost pôde migrar para um novo conceito de maior potencial, chamado de VASPS (Verticular Annular Separation and Pumping System), através da participação em consórcios tecnológicos (Furtado \& Freitas, 2000).

\subsection{A Plataforma TLP (Tension Leg Platform)}

A TLP é um tipo de plataforma que pode operar a grandes profundidades e cuja tecnologia a Petrobras não dominava à época. Em função das potencialidades dessa tecnologia, a Petrobras decidiu, a partir de um contrato de transferência de tecnologia, desenvolver um desenho próprio de TLP que fosse capaz de operar a 1.000 metros de profundidade. Foram contratadas duas empresas, 
uma norte-americana e outra sueca, para desenvolver o projeto conceitual da TLP para a Petrobras. Este foi posteriormente adaptado pela equipe técnica da estatal para operar em águas profundas. Esse esforço levou à introdução de importantes novidades, no que diz respeito ao sistema de amarração, as quais resultaram no depósito de uma patente.

O projeto não foi aplicado porque a Petrobras até hoje não optou por essa tecnologia em nenhum de seus desenvolvimentos em offshore. Entretanto, o projeto possibilitou que se gerasse, na empresa, uma importante capacitação para desenvolver sistemas de produção apoiados em TLP ou em Spar Buoys.

A UFRJ (Universidade Federal do Rio de Janeiro) envolveu-se diretamente no projeto. A equipe universitária adaptou um software, incorporando um conjunto de rotinas, para que ele pudesse tratar a aleatoriedade dos movimentos do mar. Esse conhecimento da Universidade não só foi útil para consolidar a capacitação em projetar TLP, mas também foi aplicado a sistemas flutuantes convencionais e no desenvolvimento de um novo sistema de amarração de plataformas semi-submersíveis por sucção (Tautleg).

\section{3. Árvore de Natal Molhada}

A Árvore de Natal Molhada (ANM) é um equipamento que fica na cabeça do poço, no fundo do mar, cuja função consiste em controlar a produção de hidrocarbonetos. A Petrobras estabeleceu como meta desenvolver um equipamento que fosse capaz de operar a 1.000 metros de profundidade. Havia na época, alguns fabricantes nacionais familiarizados com a produção desses equipamentos sob licença estrangeira. Os preços eram altos, além disso, inexistiam equipamentos operados a essas profundidades. A Petrobras decidiu montar uma equipe, localizada no Cenpes, capaz de fazer o projeto básico e de detalhe. $\mathrm{O}$ projeto foi bem-sucedido tecnologicamente. Chegou-se a construir um protótipo. Mas a produção comercial em larga escala não se concretizou.

O novo conceito enfrentou sérios obstáculos de transferência e de passagem para a escala industrial. Não encontrou muito interesse por parte dos fabricantes, que não quiseram licenciá-lo. Além disso, em função da demora, o próprio conceito da nova ANM acabou se tornando obsoleto.

Mesmo assim, a Petrobras realizou um aprendizado significativo, que 
resultou em importantes impactos econômicos. O fato da Petrobras, que era a principal compradora mundial desse equipamento, dispor de um conceito próprio levou as empresas estrangeiras, detentoras dessa tecnologia, a baratear o preço de venda de forma significativa. Ademais, os conhecimentos adquiridos com a concepção de ANMs serviram bastante nas próximas encomendas. As ANMs costumavam ser diferentes entre si quando provinham de uma mesma empresa. Em função do domínio adquirido em projetar esse equipamento para águas profundas, a Petrobras passou a padronizá-las. Essa padronização reduziu o tempo de instalação e de manutenção das ANMs.

\subsection{Manifold}

O Manifold, localizado no fundo do mar, é um equipamento que serve para interligar a plataforma semi-submersível com os poços submarinos. No Procap 1000, a Petrobras decidiu desenvolver um projeto de Manifold que fosse capaz de operar até 1.000 metros de lâmina d'água. Esse projeto constituiu um importante marco para o desenvolvimento da capacitação do seu laboratório de pesquisas - o Cenpes - em engenharia submarina. Inicialmente, o projeto emanou de uma demanda do Departamento de Produção da Petrobras. Porém, o Cenpes aproveitou-se dessa demanda para propor o desenvolvimento de um novo conceito. O objetivo era fazer um Manifold que pudesse ser instalado sem a ajuda de mergulhadores — diverless — para operar em águas profundas. O Cenpes decidiu introduzir uma novidade, criando um Manifold que embutia cabeças de poços (quatro ao todo), com a alegação de poupar linhas flexíveis. O Manifold podia também ser conectado a ANMs separadas.

O projeto envolveu um importante esforço de engenharia do Cenpes, que realizou a parte conceitual e o detalhamento do projeto. Foi feito um desenho preliminar. Posteriormente, contratou-se uma empresa norte-americana, para aperfeiçoar esse conceito básico. Essa empresa introduziu modificaçōes e atualizou a parte conceitual. Em seguida, a equipe do Cenpes detalhou o desenho, especificou os equipamentos e o ROR (Robô de Operação Remota) a serem usados na instalação, elaborando cinco manuais.

O equipamento era um conceito original que custava entre US\$25 e 30 
milhões. Depois de pronto, o Departamento de Produção da Petrobras não se interessou por ele porque não convergia com a sua cultura operacional, que era a de usar ANMs separadas do Manifold. A Petrobras acabou descartando o equipamento.

O projeto gerou um importante aprendizado. Foram depositadas quatro patentes. A equipe da Petrobras adquiriu domínio sobre o detalhamento de projetos de Manifolds. Esse conhecimento foi muito útil na hora de fazer novos projetos. Primeiro, ele serviu no detalhamento do Octos 1000, que será apresentado a seguir. Posteriormente, foi usado para encomendar Manifolds a fabricantes nacionais. Em função de uma maior adaptação dos projetos conceituais aos campos da Petrobras, logrou-se reduzir substancialmente os custo desses Manifolds.

\subsection{Octos 1000}

Trata-se de projeto original em sua concepção, por não emanar diretamente do Cenpes. O conceito de um novo Manifold, adequado para operar até 1.000 metros de lâmina d'água nas condiçóes específicas da Bacia de Campos, surgiu no Departamento de Perfuração da Petrobras, que logo decidiu mobilizar uma equipe para desenvolvê-lo. Esse projeto correu paralelamente ao do Cenpes, que foi visto no item anterior. Ele contou com a colaboração de um fabricante de equipamentos nacional, que desenvolveu a parte de engenharia do projeto. Em 1988, o projeto conceitual ficou pronto, obtendo imediatamente aceitação internacional. Por isso foi incorporado ao Procap 1000. Em seguida, todas as equipes da Petrobras, inclusive a do Cenpes, envolveram-se no desenvolvimento desse conceito (projeto básico + projeto de detalhe). Chegou-se a fazer um estudo de viabilidade técnico-econômico e o projeto foi logo aprovado. Um campo inteiro deveria operar com vários Octos. A grande vantagem do Octos consistia em poder operar sobre terrenos arenosos.

A Unicamp foi chamada a participar dessa parte do projeto realizando o dimensionamento e o cálculo estrutural. A engenharia de detalhe ficou a cargo do fabricante nacional. O detalhamento do projeto foi relativamente demorado. Mas o problema maior consistiu na própria incerteza do processo de inovação que conduziu a mudanças de rota nas decisões de investimento da empresa. A perfuração de um poço seco em Albacora levou a empresa a rever seu 
projeto inicial de desenvolvimento do campo. Quando o novo projeto foi elaborado, a alternativa do Octos 1000 terminou sendo descartada por ser demasiadamente cara.

Embora o conceito do Octos 1000 tenha sido descartado, a Petrobras aprendeu bastante com a sua execução. Graças ao projeto, a empresa adquiriu domínio sobre técnicas de instalação de equipamentos de produção no fundo do mar, as quais passaram a ser incorporadas em novos projetos, possibilitando importantes ganhos econômicos. Esse ganho foi tecnológico, mas também organizacional. O projeto possibilitou que técnicos de diferentes departamentos da Petrobras passassem a trabalhar juntos; também permitiu a formação de recursos humanos (equipes e competências) nos participantes externos (fornecedor e universidade). O fornecedor se capacitou a desenhar e fabricar Manifolds, campo em que não atuava anteriormente.

\subsection{Vitória-Régia}

A Vitória-Régia foi o projeto do Procap 1000 que objetivava desenvolver uma plataforma semi-submersível de produção para águas profundas. No contexto da estratégia nacionalista da Petrobras, o primeiro passo do processo de aprendizagem consistiu em adquirir, de fornecedores estrangeiros, o projeto conceitual de uma plataforma semi-submersível de perfuração (mais freqüentes na indústria internacional) para águas rasas (menos de 400 metros). No contrato de transferência, incluiu-se uma cláusula que exigia a transferência dos conhecimentos básicos para os técnicos da Petrobras. Após seu domínio, houve adaptação desses conceitos para a produção e operação em águas profundas. Esse processo levou à construção da P-XVIII, que foi a primeira plataforma de produção nova para águas profundas encomendada pela Petrobras.

O projeto da Vitória-Régia constitui-se no ápice do processo de aprendizagem tecnológica, em matéria de plataformas semi-submersíveis, realizado pela Petrobras durante a década de 1980 . O projeto consistia no desenvolvimento de um novo conceito de plataforma semi-submersível mais apropriado ao ambiente operacional da Bacia de Campos e capaz de operar até 1.000 metros de lâmina d'água. Esse novo conceito implicaria numa redução de custo fixo de em torno de $30 \%$. 
O projeto básico desenvolvido pelo Cenpes foi concluído com sucesso, obtendo certificação. Entretanto, a Vitória-Régia enfrentou sérios obstáculos internos que inviabilizaram a sua efetiva aplicação comercial. Houve desentendimentos entre o Cenpes e o seu principal cliente que era o Departamento de Produção da Petrobras. Este queria uma plataforma com capacidade de conter um maior volume e sustentar um maior peso em equipamentos (geração e compressores). A adaptação do projeto às necessidades do cliente tornou-se inviável operacionalmente. Por outro lado, a Petrobras alterou sua estratégia de aquisição de plataformas semi-submersíveis. A empresa decidiu adotar a solução mais barata de reconverter as plataformas de perfuração, as quais sobravam à época no mercado internacional em função dos baixos preços do petróleo, no lugar de encomendar plataformas novas de produção.

Mesmo sem aplicação comercial, o projeto da Vitória-Régia foi um marco importante para a consolidação da capacitação tecnológica em engenharia de plataformas no País. Os conhecimentos adquiridos com a redução de peso da plataforma e a compactação dos equipamentos foram aplicados em projetos da Petrobras de reconversão de plataformas, permitindo importantes ganhos econômicos.

\subsection{Robô de Operação Remota (ROR)}

O projeto é singular pois contrariamente aos demais que, em grande medida, resultaram de esforços internos da Petrobras, o desenvolvimento do ROR foi encomendado integralmente a um fabricante nacional. Esse projeto consistiu numa solicitação do Departamento de Perfuração da Petrobras de dois robôs de observação capazes de operar até 1.000 metros de lâmina d'água.

Desde o início, essa empreitada enfrentou sérias dificuldades. A escolha de desenvolver robôs de observação não foi apropriada, pois a tendência da indústria era de robôs versáteis capazes de observar e intervir simultaneamente. A equipe da Petrobras, que monitorava o projeto, não soube introduzir as mudanças de curso necessárias.

O elevado índice de nacionalização do projeto (94\%) levou o fabricante nacional a contratar quatro empresas e quatro institutos de pesquisa nacionais 
para desenvolver e construir partes do equipamento. Era a primeira vez que uma empresa nacional fabricava um robô submarino, com esse índice de nacionalização e operando a 1.000 metros de lâmina d'água. Tratava-se de uma proeza em nível internacional.

Desse grande esforço resultaram dois ROR que não lograram operar adequadamente. $\mathrm{O}$ fabricante foi chamado para introduzir reparos, havendo uma melhora de desempenho. Porém, os equipamentos acabaram sendo abandonados (um perdeu-se e outro não funcionou). Não houve continuidade nas operações porque a Petrobras mudou a política de compra e passou a alugar os robôs ao invés de adquiri-los.

O ROR não chegou a ser um fracasso tecnológico, porém foi certamente um fracasso comercial. Contudo, esse projeto possibilitou um importante processo de aprendizagem por parte do fabricante nacional e da Petrobras.

O fabricante, graças ao projeto, capacitou-se para atuar no mercado de operação/aluguel de robôs. Essa maior capacitação do fabricante nacional teve um importante impacto concorrencial que beneficiou a Petrobras, ao baixar o preço do aluguel de robôs no mercado nacional.

Em função de conhecimentos adquiridos na construção de robôs, o fabricante desenvolveu novos equipamentos. Também formaram-se importantes competências em recursos humanos no fabricante nacional e na Petrobras.

\section{Impactos econômicos}

A avaliação de impactos econômicos do Procap 1000 (Furtado et al., 1998) tornou possível uma visão mais concreta da importância relativa das diferentes formas de aprendizagem obtidas a partir dos sete projetos nacionalistas. A primeira constatação é de que os projetos nacionalistas, apesar de não terem sido aplicados diretamente, geraram importantes impactos econômicos para os participantes do programa, os quais somados são muito superiores ao custo total dos projetos de $\mathrm{P} \& \mathrm{D}$. Ao todo, a relação impacto/custo, contabilizando-se os impactos ocorridos e previstos, ${ }^{5}$ foi de 6,97 , sendo maior para as entidades de pesquisa $(9,64)$, seguidas pela Petrobras $(7,17)$ e pelos

5 A metodologia de avaliação do BETA é de recorte temporal ex post. Porém, ela possibilita a projeção de impactos de atividades e investimentos que estão em curso (ver Anexo). 
fabricantes nacionais $(6,06)$. Restringindo-se a mensuração apenas aos impactos ocorridos até o momento da avaliação, realizada em 1997-98, a relação impacto/custo era de 5,77, sendo apenas superior a da Petrobras $(5,67)$. Até cinco anos após a conclusão do Procap 1000, já haviam sido efetivados $82,9 \%$ dos impactos econômicos dos projetos nacionalistas (Tabela 1).

Embora a maior parte dos impactos tenha ocorrido na Petrobras, os fornecedores que participaram dos projetos obtiveram ganhos substanciais (17,5\% dos impactos). Como os projetos nacionalistas quase não tiveram aplicação comercial direta, os impactos diretos foram pouco significativos, $7,6 \%$ do total de impactos. Em compensação, a maior parte dos impactos foram indiretos, ou seja, resultaram de aplicaçôes que fugiam ao escopo inicial dos projetos. Entre os impactos indiretos, os tecnológicos foram os mais importantes $(50,8 \%)$, sendo seguidos pelos comerciais $(22,2 \%)$, em recursos humanos $(13,4 \%)$ e organizacionais $(6 \%)$.

Os impactos tecnológicos em processo foram muito importantes para a Petrobras porque os novos conhecimentos, adquiridos através dos projetos, permitiram aprimorar os processos de extração de hidrocarbonetos. $\mathrm{O}$ segundo ganho mais importante dos projetos nacionalistas consistiu em melhorar a capacidade de negociação da empresa, repercutindo favoravelmente no preço de equipamentos adquiridos. Um ganho semelhante pôde ser comprovado com o lançamento da Central Telefônica Trópico, desenvolvida pelo CPqD da Telebrás. O preço das centrais dos concorrentes estrangeiros caiu substancialmente no mercado brasileiro (Cruz, 2000). Em terceiro lugar, vem os impactos na formação de massa crítica e, em quarto, os de mudança organizacional. A mudança organizacional foi um importante aspecto da aprendizagem tecnológica obtida pelos projetos nacionalistas. Por meio destes logrou-se estreitar os canais de comunicação, anteriormente muito falhos, entre o Departamento de P\&D (Cenpes) e os departamentos operacionais.

Os fornecedores obtiveram também significativos impactos indiretos, sobretudo através da abertura de novos mercados (serviços e produtos). Mas a participação nos projetos foi uma excelente oportunidade para consolidar as equipes de engenharia com competências-chave dentro dessas empresas (massa crítica). 
TABELA 1

Custo e Impactos Diretos e Indiretos dos Projetos (em mil R\$ de novembro de 1996)

\begin{tabular}{|c|c|c|c|c|c|}
\hline & Petrobras & Universidades & Fornecedores & Total & $(\%)$ \\
\hline Custo & 12.680 & 132 & 3.343 & 16.155 & \\
\hline \multicolumn{6}{|l|}{ Impactos } \\
\hline Diretos & 8.722 & & & 8.722 & 7,6 \\
\hline Indiretos & 85.785 & 1.277 & 20.257 & 107.320 & 92,4 \\
\hline Tecnológicos & 40.346 & 181 & 18.491 & 59.018 & 50,8 \\
\hline Produto & & 181 & 1.979 & 2.160 & 1,9 \\
\hline Processo & 40.326 & & & 40.326 & 34,7 \\
\hline Serviço & & & 16.512 & 16.512 & 14,2 \\
\hline Patentes & 20 & & & 20 & 0,0 \\
\hline Organizacional & 6.980 & & & 6.980 & 6,0 \\
\hline Mudança Organizacional & 6.980 & & & 6.980 & 6,0 \\
\hline Comercial & 25.767 & & & 25.767 & 22,2 \\
\hline Novos Projetos & 1.006 & & & 1.006 & 0,9 \\
\hline Concorrencial & 24.761 & & & 24.761 & 21,3 \\
\hline Recursos Humanos & 12.693 & 1.097 & 1.766 & 15.556 & 13,4 \\
\hline Massa Crítica & 12.351 & 476 & 1.766 & 14.593 & 12,6 \\
\hline Formação de RH & 342 & 621 & & 963 & 0,8 \\
\hline Total Impactos até 2006 & 94.557 & 1.277 & 20.257 & 116.092 & 100,0 \\
\hline Impactos/Custos até 2006 & 7,46 & 9,64 & 6,06 & 7,19 & \\
\hline Total Impactos até 1997 & 74.724 & 1.277 & 20.257 & 96.198 & 82,9 \\
\hline Impacto/Custo até 1997 & 5,67 & 9,34 & 6,06 & 5,77 & \\
\hline
\end{tabular}

Fonte: Furtado et al.,1998.

As universidades, como era de se esperar, obtiveram impactos econômicos em recursos humanos. Porém esses ganhos ocorreram, em maior proporção, através da qualificação de recursos humanos (formação de RH), do que propriamente na constituição de equipes (massa crítica). 


\section{As diferentes formas de capacidade de absorção}

Embora os projetos nacionalistas tenham engendrado uma grande variedade de formas de aprendizagem que resultaram em diferentes capacitações, pode-se considerar que a capacidade de absorção foi uma das principais competências que eles reforçaram. Para entender como agiram sobre a capacidade de absorção dos participantes, convém analisar em profundidade os processos de aprendizagem tecnológica dos projetos do Procap 1000.

Com efeito, não existe ainda uma noção bem clara do que venham a ser as diferentes formas de aprendizagens (tecnológica, organizacional, relacional) e como elas podem vir a resultar em ganhos econômicos. Como postulam Cohen e Levinthal (1989), a P\&D possui uma dupla face. Por um lado, gera novos conhecimentos tecnológicos. Por outro, incrementa a capacidade de fazer uso dos conhecimentos externos. É um tipo de atividade que quando bem conduzida pode levar a importantes formas de aprendizado, além dos resultados diretos que podem emanar dela. A primeira questão seria por que a $P \& D$ é um tipo de atividade que gera tanto aprendizado, embora não seja a única. A resposta sugerida pelos autores deste trabalho consiste em que a P\&D não é uma atividade rotineira, superando, portanto, a limites do learning by doing (Arrow, 1962). Muito freqüentemente ela gera novos conhecimentos de como fazer coisas que podem ser úteis em situações distintas.

$A$ atividade de P\&D se estrutura em torno de objetivos específicos. Os resultados diretos do projeto (novo produto, processo ou serviço) são concebidos para atender a necessidades estabelecidas nos objetivos. Porém de que forma emanam os impactos indiretos ou os spin-offs? O projeto, além de se propor a alcançar determinados objetivos, contribui para aumentar o estoque de conhecimentos das empresas e, também, a melhorar sua aptidão em fazer uso desse recurso para novas finalidades. Essa aptidão serve, da mesma forma, para fazer uso dos conhecimentos externos.

A capacidade de fazer uso dos conhecimentos internos para encontrar-lhes novas aplicações pode gerar diversos tipos de impactos indiretos. A capacidade, obtida através da P\&D, de absorver os conhecimentos externos, pode ser considerada como outra modalidade de aprendizado que engendra, também, diversos tipos de impactos indiretos: tecnológicos, organizacionais e relacionais. 
$\mathrm{Na}$ avaliação dos projetos nacionalistas, essas duas capacidades de usar tanto o conhecimento interno quanto externo foram consideradas simultaneamente.

A análise detalhada dos projetos possibilitou compreender com maior grau de precisão como se concretiza a capacidade de absorção. Trata-se de um conceito bastante amplo que engloba várias habilidades da empresa para fazer uso de conhecimentos externos. Pode-se identificar algumas das formas mais específicas com que a capacidade de absorção se reveste, as quais merecem atenção particular:

1. Capacidade de negociação: através da experiência adquirida com a P\&D, uma organização pode obter melhores conhecimentos sobre os verdadeiros custos da tecnologia de um fornecedor. Esse novo conhecimento sobre o hardware pode ajudar também na busca de fornecedores alternativos que tenham capacidade para fabricar competitivamente os equipamentos. Essa capacidade está por trás dos impactos comerciais concorrenciais identificados pelo estudo de avaliação do Procap 1000 (Furtado et al., 1998).

2. Especificação de conhecimento crítico sobre novos equipamentos: o conhecimento adquirido com o desenvolvimento, construção e teste de um protótipo pode ser de grande valia para se conhecer a fundo os seus componentes e partes. Esse conhecimento pode ser reutilizado como especificação técnica na encomenda de um equipamento distinto. Isto permite que o fornecedor tenha acesso a um importante conhecimento do comprador, que por sua vez se beneficia com a aquisição de equipamentos melhorados.

3. Capacidade de acompanhar os avanços internacionais: o projeto, nesse caso, volta-se para o monitoramento e o desenvolvimento de tecnologias de fronteira, em nível internacional. Em função da experiência adquirida no projeto, a empresa consegue acompanhar as novas evoluções tecnológicas internacionais.

4. Flexibilidade (escapar ao lock in): o projeto se destina a desenvolver conceitos próprios em tecnologia de fronteira. Mesmo que o conhecimento desenvolvido no projeto não chegue ao mercado, a empresa adquire uma capacitação tecnológica suficiente que lhe permite migrar para conceitos mais promissores.

5. Capacidade de adaptação: o projeto, que se apóia na transferência e adaptação de conhecimentos externos, gera uma capacitação específica de adap- 
tar conhecimentos externos. Essa capacidade de adaptação é posteriormente usada em novos conceitos adquiridos externamente.

6. Capacidade de uso de novas tecnologias: o projeto possibilita à empresa que o desenvolve (fabricante) dominar não apenas a tecnologia de fabricação de um novo equipamento, mas também a de operação e a de manutenção. Com isto a empresa se habilita a ser um usuário qualificado desse equipamento, podendo resultar em uma nova atividade econômica.

O Quadro 2 apresenta quais foram as principais formas de capacidade de absorção que resultaram dos projetos nacionalistas da Petrobras. A especificação de conhecimentos críticos (2) e a adaptação de tecnologias adquiridas externamente (5) foram as formas mais freqüentes de aprendizado tecnológico que repercutiram favoravelmente na capacidade de absorção das organizações envolvidas nos projetos.

QUADRO 2

Formas de Capacidade de Absorção Adquiridas pelos Projetos Nacionalistas do Procap 1000

Bombeio Submarino

TLP

ANM

Manifold

Octos 1000

Vitória-Regia

$\mathrm{ROR}$

4

$x$

$x$

$x$

$x$

$x$

$x$

Os projetos voltados a tecnologias de fronteira tiveram importantes desdobramentos nas capacitações (3), (4) e (6) (acompanhamento da fronteira tecnológica, flexibilidade e uso de novas tecnologias).

As formas pelas quais as diferentes capacidades de absorção se traduziram em impactos econômicos, conforme a metodologia de avaliação econômica do 
BETA, é complexa. O Quadro 3 representa as formas de impactos indiretos gerados através das distintas capacidades de absorção.

QUADRO 3

Relações entre as Formas de Capacidade de Absorção com os Impactos Econômicos dos Projetos Nacionalistas do Procap 1000

\begin{tabular}{|c|c|c|c|c|c|c|}
\hline \multirow{3}{*}{$\begin{array}{l}\text { Fontes de } \\
\text { Conhecimento } \\
\text { Impactos }\end{array}$} & \multicolumn{3}{|c|}{ Interna } & \multicolumn{3}{|c|}{ Externa } \\
\hline & \multirow[t]{2}{*}{ Direto } & \multicolumn{2}{|c|}{ Indireto } & \multicolumn{3}{|c|}{ Indireto } \\
\hline & & Tecnológico & Comercial & Tecnológico & Organizacional & Comercial \\
\hline Projetos & Aplicação & $\begin{array}{c}\text { Novos } \\
\text { Produtos e } \\
\text { Processos }\end{array}$ & Redes & $2,3,4,5$ e 6 & 2 & 1 \\
\hline
\end{tabular}

A capacidade de absorção está relacionada com uso de conhecimentos externos e a sua aplicação produtiva. No caso da Petrobras, as diferentes capacidades de absorção (2), (3), (4), (5) e (6) estavam por trás de impactos tecnológicos. Ao passo que apenas a capacidade de absorção (2 - Especificação de conhecimento crítico) resultou em impactos organizacionais e a capacidade de absorção (1 - Capacidade de negociação) em impactos comerciais. A capacidade (1) estava diretamente relacionada aos impactos comerciais concorrenciais. Ao passo que a capacidade (2) associou aprendizado tecnológico com a cooperação entre o Departamento de P\&D e os departamentos de Compra e de Produção.

\section{Conclusão}

Este artigo teve por objetivo principal demonstrar a importância dos aprendizados tecnológico, organizacional e relacional (concorrencial) para o processo de inovação. Utilizou-se o caso de projetos tecnológicos nacionalistas do Programa de Águas Profundas da Petrobras (Procap 1000) para ilustrar a tese de que, mesmo em caso de projetos com insucesso comercial, as atividades de P\&D, quando bem conduzidas, podem gerar importantes impactos econô- 
micos. Os dados obtidos pelo estudo de avaliação desse programa permitiram elucidar que os impactos econômicos foram expressivos para o conjunto dos participantes em sete projetos nacionalistas. Os impactos indiretos foram muito significativos porque os projetos nacionalistas exigiram um importante esforço tecnológico em diferentes etapas do processo de inovação (concepção, detalhamento de projeto e construção de protótipo).

Por outro lado, buscou-se mostrar que as diversas formas de aprendizado derivadas da execução dos projetos estão relacionadas ao aumento da capacidade de absorção dos participantes. Identificou-se, através da análise dos casos, seis formas de capacidade de absorção. Esboçou-se uma tentativa de cruzamento entre essas diferentes capacidades com os impactos econômicos da metodologia do BETA, a qual é ainda exploratória.

\section{Bibliografia}

Alveal Contreras, C. E., Os Desbravadores e a Construção do Brasil Industrial, Rio de Janeiro: Ed. Relume Dumará - Anpocs, 1994.

Arrow, K., "Economic Welfare and the Allocation of Resources for Invention", in Nelson, R. (org.), The Rate and Direction of Inventive Activity, Princeton University Press, 1962.

Bach, L, "M. Measuring and Managing Spinoffs: The Case of Spinoffs Generated by ESA Programs", in Space Economics, 144, p.171-206, 1992.

; Molist, N. C.; Ledoux, M. J.; Matt, M.; Schaeffer, V., "Evaluation of the Economic Effects of Brite-Euram Programs on the European Industry", in Anais do Eunetics Conference: Evolutionary Economics of Technichal Change: Assessment of results and new frontiers, Strasbourg: BETA, October 6-7-8, p.971-996, 1994.

; Furtado, A.; Gilles, L., "Variété des Programmes de R\&D, Variété des Méthodes d'Évaluation, Variété des Évaluation, Variété des Effects Économiques — Quelques Enseignements Tirés de l'Application de la Méthode du BETA à Différents Programmes de R\&D”, in Textos para Discussão N. 29, p. 10-43, Campinas: DPCT/IG/UNICAMP, 1998.

Bell, R. M., "Learning and the Accumulation of Industrial Technological Capacity in Developing Countries, in Fransman, M.; King, K., Technological Capability in the Third World, Londres: Macmillan, 1984. 
Cano, P. Q.; Cano, C. P., “Capacidad de Absorción: un Estudio Empírico de la Naturaleza de la Variable”, in Memoria ALTEC 2001, IX Seminario Latino-Iberoamericano de Gestión Tecnológica en la Economía del conocimiento, Costa Rica, 17-19, out., 17 p., 2001.

Cohen, W. M.; Levinthal, D. A., “Absorptive Capacity: A New Perspective on Learning and Innovation”, in The Economic Journal, v.99, 569-596, set., 1989.

Cruz, A. B., "A Universidade, a Empresa e a Pesquisa que o País Precisa”, in Parcerias Estratégicas, 8, maio, Ministério da Ciência e Tecnologia, Brasília, 2000.

Dahlman, C.; Westphall, L., “Technological Effort in Industrial Development — an Interpretative Survey of Recent Research", in Stewart, F.; James, J. (orgs.), The Economics of New Technology in Developing Countries, Londres: Frances Pinter, p.105-137, 1982.

Dosi, G., "The Nature of Innovative Process", in Dosi, G. et al. (orgs.), Technical Change and Economic Theory, Londres \& Nova York: Pinter Publisher, p.221-238, 1988.

Erber, F., "Política Industrial: um Debate que Tornou-se Urgente", in Revista Brasileira de Tecnologia, v.19, n.1, jan., p.20-16, 1988.

Fransman, M.; King, K. (orgs.), Technological Capability in the Third World, Baltimore: Basingstoke, 1984.

Freeman, C., La Teoria Economica de la Inovacion Industrial, Madri: Alianza Universidad, 1974.

Furtado, A.; Freitas, A. G., "The Catch-up Strategy of Petrobras Through Cooperative R\&D”, in Journal of Technology Transfer, 25, p.23-36, 2000.

; Pereira, N. M.; Suslick, S.; Freitas, A. G.; Furtado, R.; Bach, L., Avaliação de Grandes Programas Tecnológicos : o Procap 1000 (FASE II: Estudo Abrangente do Programa). Relatório Final, Campinas, dez., 1998.

"Assessment of Direct and Indirect Effects of Large Technological Programmes: Petrobras Deepwater Programme in Brazil”, in Research Evaluation, 8(3), dez., p.155-163, 1999.

George, G.; Zahra, S. A.; Wheatley, K. K.; Khan, R., "The Effects of Alliance Portfolio Characteristics and Absorptive Capacity on Performance A Study of Biotechnology Firms", in Journal of High Technology Management Research, v.12, p. 205-226, 2001.

Griliches, Z., "Issues in Assessing the Contribution of Research and Development to Productivity Growth", in Bell Journal of Economics, 10, p.92-116, 1979.

Katz, J., “Importación de Tecnología y Desarrollo Dependiente”, in French-Davies, R. (org.), Intercambio y Desarrollo, México: Fondo de Cultura Económica, El Trimestre Económico, Serie de Lecturas nº 38, v.2, p.193-213, 1981. 
Kim, L., "Stages of Development of Industrial Technology in a Developing Country: A Model”, in Research Policy, v.9, n.3, p.254-277, 1980.

"Building Technological Capability for Industrialization: Analytical Framewoks and Korea's Experience", in Industrial and Corporate Change, v.8, n.1, p.111-136, 1999.

Kline, S; Rosenberg, N., “An Overview of Innovation”, in Landau, R; Rosenberg, N. (orgs.), The Positive Sum Strategy, Washington, DC: National Academy of Press, 1986.

Lall, S., “Technological Learning in the Third World: Some Implications of Technological Exports”, in Stewart, F.; James, J. (orgs.), The Economics of New Technology in Developing Countries, Londres: Frances Pinter, p.157-179, 1982.

,"Technological Capabilities and Industrialization”, in World Development, v.20, n.2, p.165-182, 1992.

Mansfield, E., "Academic Research and Industrial Innovation", in Research Policy, v.20, p.1-12, 1991.

Martins, L., Pouvoir et Développement Economique, Paris: Anthropos, 1976.

Nelson, R. R.; Winter, S., An Evolutionary Theory of Economic Change, Cambridge, Mass.: Belknap Press of Harvard University Press, 1982.

, "Capitalism as an Engine of Progress", in Inose, H.; Kawasaki, M.; Kodama, F. (orgs.) Science and Technology Policy Research "What should be done?" "What can be done", The Proceedings of the NISTEP International Conference on Science and Technology Policy Research, Tóquio, Japão: Mita Press, 1991.

Peris, L. F.; Mestre, J. O., "Influencia de las Capacidades de Absorción sobre las Actividades Innovadoras de la Empresa", in Memoria ALTEC 2001, IX Seminario Latino-Iberoamericano de Gestión Tecnológica en la Economía del conocimiento, Costa Rica 17-19 out., 15 p., 2001.

Rosenberg, N., Tecnologia y Economia, Barcelona: G. Gilli, 1979.

Schneider, B. R., Politics Within the State. Elite Burocrats and Industrial Policy in Authoritarian Brazil. Pittsburgh, Pa.: Ed. University of Pittsburgh Press, 1991.

Tapia, J. R. B., A Trajetória da Política de Informática Brasileira (1977-1991), Campinas-SP: Ed. Papirus, 1995.

Veugelers, R., "Internal R\&D Expenditures and External Technology Sourcing”, in Research Policy, v.26, p.303-315, 1997. 


\section{Anexo}

\section{Metodologia de Avaliação do Procap 1000}

O estudo de avaliação de impactos econômicos do Procap 1000 se apoiou na metodologia desenvolvida pelo BETA da Universidade de Estrasburgo que divide os impactos econômicos de programas tecnológicos em diretos e indiretos (Bach et al., 1992, 1994). O ponto de partida dessa abordagem é o da sociedade. Os grandes programas tecnológicos são percebidos como um instrumento de melhora do bem-estar social. Por essa razão, busca-se quantificar os impactos econômicos dos projetos em termos de aumento do PIB e não apenas do lucro empresarial.

Essa abordagem define duas modalidades de impactos econômicos. Os impactos diretos decorrem da aplicação direta dos resultados dos projetos de $P \& D$, enquanto os impactos indiretos resultam de diversas formas de aprendizagem obtidas ao longo do projeto. A metodologia especifica quatro tipos de impactos indiretos. Cada tipo de impacto corresponde a uma forma definida de aprendizagem resultante da realização do programa. $\mathrm{O}$ trabalho do BETA destaca diferentes formas de aprendizagem — a tecnológica, a organizacional e a relacional ou comercial - , das quais decorrem diferentes tipos de impacto econômico. Muitas vezes essas distintas formas de aprendizagem fazem parte de uma mesma inovação. Além desses três impactos, há o impacto em recursos humanos, que mede o aumento do estoque de capacitações incorporadas em pessoas proporcionada pelo programa

Entretanto, apesar de se apoiar numa perspectiva do interesse social, essa abordagem é de corte essencialmente microeconômico, ao contrário do enfoque econométrico da função de produção de certos estudos (p. ex. Griliches, 1979). Os dados são levantados através de pesquisa direta na empresas, e não no uso de agregados econômicos. Esse enfoque restringe a avaliação dos impactos apenas aos participantes do projeto. Os impactos são medidos através da variação que o projeto causa no valor agregado dos participantes envolvidos, salvo em certas oportunidades quando os custos são usados como uma proxy desse valor.

Ora, quando a difusão de uma inovação ocorre, tanto os impactos diretos quanto indiretos costumam se estender a um número bem maior de agentes econômicos do que ao próprio inovador. Por isso, o enfoque do BETA, ao 
incluir apenas os participantes de um determinado programa, avalia parcialmente os ganhos, ou até mesmo as perdas, oriundas da inovação. Alguns estudos, que partiram de uma perspectiva microeconômica mas buscaram quantificar a relação entre os ganhos obtidos pelos usuários de uma inovação e os inovadores, estimaram que essa relação fosse de oito (Mansfield, 1991). Outra característica "minimalista" dessa abordagem metodológica consiste sempre em optar por quantificar apenas os impactos mínimos dos projetos, quando existe uma incerteza quanto a estes.

A metodologia do BETA também inovou ao estabelecer um coeficiente de paternidade do programa sobre o impacto. Esse coeficiente mede a efetiva contribuição do projeto/programa para que um determinado impacto se efetivar.

Dada a complexidade que envolve o levantamento de dados junto aos projetos e o grande número deles existente em um programa tecnológico, a metodologia do BETA se apóia numa amostra representativa dos projetos de um programa.

A metodologia do BETA foi usada para mensurar diversas formas de impactos econômicos que decorreram da aprendizagem obtida com os projetos, atendendo aos objetivos deste trabalho que busca demonstrar a importância da aprendizagem obtida a partir de projetos de orientação nacionalista.

A seguir será apresentada uma breve descrição dos impactos e dos métodos de quantificação usados pela pesquisa.

\section{Impactos diretos}

São aqueles impactos relacionados apenas aos objetivos iniciais do projeto. Decorrem da aplicação em escala comercial do novo conhecimento por ele gerado, conhecimento este que estava explicitamente incluído em suas metas iniciais. Por exemplo, se o objetivo do projeto era desenvolver um determinado equipamento, o impacto direto seria o aumento do valor agregado obtido a partir da comercialização desse produto. Se, por outro lado, o objetivo for desenvolver um novo processo, os impactos consistem na redução de custo provocada pela introdução desse novo processo.

\section{Impactos indiretos}

Já os impactos indiretos são definidos de uma forma bem mais ampla,

82 Revista Brasileira de Inovação 
englobando todo tipo de resultado não previsto nos objetivos explícitos do projeto. Esses impactos podem estar relacionados a mesma atividade que gerou o projeto desde que escapem ao seu escopo inicial. De forma que o conceito de spin-off que foi adotado não se refere apenas a aplicação em uma atividade tecnologicamente ou setorialmente diferente de novos conhecimentos gerados pelo projeto, mas resulta também de desdobramentos que foram inicialmente imprevistos pelos objetivos.

Os seguintes impactos merecem uma atenção especial:

\section{Impactos tecnológicos}

Dizem respeito à transferência de tecnologia oriunda das atividades do projeto para outras atividades. Pode consistir em qualquer tipo de transferência dos conhecimentos adquiridos ao longo do projeto para uma aplicação que não estava dentro dos objetivos iniciais do projeto. Como pudemos comprovar no caso do estudo do Procap essa transferência pode ocorrer entre atividades muito similares tecnologicamente. A transferência tecnológica ocorre das seguintes formas:

— novos produtos

- novos processos

— serviços tecnológicos

- patentes: são ativos intangíveis criados pela organização que representam um valor em si independente da transferência de tecnologia. São unicamente contabilizados quando a patente não é comercializada.

\section{Impactos comerciais}

Consistem no aumento de atividade econômica ocasionada pelo estabelecimento de novas relaçôes com os parceiros comerciais que não incorpora propriamente um aporte significativo de novo conhecimento tecnológico proveniente do projeto. São os seguintes:

- impactos de rede: provenientes das relações entre participantes de um mesmo consórcio, que conduz ao estabelecimento de laços de colaboração depois do projeto concluído;

- impactos de reputação: que ocorrem quando os participantes obtêm, a partir das atividades do projeto, um maior reconhecimento e visibilida- 
de externa, a qual se traduz num aumento das vendas. Um caso possível é a obtenção de certificado de qualidade que repercute na imagem externa da empresa;

— impactos concorrenciais: que decorrem de novas parcerias e novas oportunidades de mercado obtidas em decorrência da aprendizagem realizada com o projeto. Muitas vezes a execução do projeto permite a empresa aprender melhor como funcionam determinados mercados e ter maior acesso aos competidores, logrando dessa forma melhorar as condiçōes concorrenciais existentes em alguns mercados, monopolizados por certos fornecedores. Esse ganho foi identificado pelo estudo de avaliação do Procap (Furtado et al., 1998).

\section{Impactos organizacionais e de métodos}

A introdução do projeto deixa suas marcas na cultura e na estrutura organizacional dos participantes. A forma como são conduzidas as atividades rotineiras que resultam em inovações e melhoramentos vê-se alterada de forma importante. Os impactos que podem ser abordados são:

— habilidade em gerenciar projetos: a partir da implantação do projeto a entidade envolvida adquire maior capacidade para gerenciar novos projetos de pesquisa;

- impactos organizacionais: quando o projeto implica numa mudança da estrutura organizacional da firma. Por exemplo, quando conduz à formação de um departamento de P\&D ou de Qualidade;

—impactos metodológicos: quando novos métodos organizacionais implementados no projeto são transferidos para outras atividades.

\section{Impactos em recursos humanos}

A execução das diversas tarefas do projeto implica na contratação de novos recursos humanos e na realização de um esforço de treinamento específico pela entidade envolvida. Ademais, os quadros adquirem um importante volume de experiência que resulta do processo de aprendizagem adquirido durante essa execução. Esses impactos resultam em maior competência e capacitação tecnológica, aumentando o volume de ativos intangíveis da firma ou entidade.

84 Revista Brasileira de Inovação 


\section{Quantificação dos impactos}

A maioria dos impactos diretos e indiretos pode ser quantificada em termos do aumento de valor agregado gerado ou de redução de custos. Quando se torna muito difícil quantificar os impactos nesses termos, usa-se o custo como proxy. Por exemplo, para uma nova patente utiliza-se o custo de registro e de obtenção; para os impactos em RH (Recursos Humanos), empregase o custo de manter uma dada competência após o projeto findar ou os gastos de treinamento; para os impactos organizacionais, é necessário o orçamento do novo departamento criado a partir do projeto. No Quadro 4 apresentam-se os principais métodos de quantificação dos impactos:

\section{QUADRO 4}

Principais Variáveis Utilizadas para Quantificar os Impactos

\begin{tabular}{|c|c|c|}
\hline \multicolumn{2}{|c|}{ Tipos de Impactos } & \multirow{2}{*}{ Quantificação } \\
\hline Impactos Diretos & & \\
\hline \multicolumn{3}{|l|}{ Impactos Indiretos } \\
\hline \multirow[t]{4}{*}{ Tecnológicos } & Transferência de produtos & vendas/novos contratos de pesquisa \\
\hline & Transferência de processos & redução de custos/novos contratos de pesquisa \\
\hline & Transferência de serviços & vendas/novos contratos de pesquisa \\
\hline & Patentes & custo de patenteamento \\
\hline \multirow[t]{2}{*}{ Comerciais } & Impactos de rede & vendas/redução de custos/novos contratos de pesquisa \\
\hline & Efeitos de reputação & \\
\hline Organizacionais & Gerenciamento de projeto & redução de custos/novos contratos de pesquisa \\
\hline \multirow[t]{2}{*}{ e de Métodos } & Organização & redução de custos/vendas/orçamento \\
\hline & Métodos & redução de custos \\
\hline \multirow[t]{2}{*}{$\mathrm{RH}$} & Competência & equivalente monetário em homens-horas \\
\hline & Treinamento & \\
\hline
\end{tabular}

Fonte: Bach et al., 1994. 


\section{Coeficiente impacto/custo}

O coeficiente impacto/custo é usado para medir o impacto dos projetos avaliados sobre os participantes do programa. Esse indicador resulta da razão entre os impactos econômicos gerados pelos participantes com o valor dos recursos investidos pela Petrobras nos projetos. O custo de P\&D de um projeto não representa o custo total de uma inovação. Por outro lado, o impacto medido em termos de valor agregado mede muito mais do que apenas o benefício gerado por uma determinada tecnologia. Por isso o indicador impacto/custo é diferente de um indicador de custo/benefício convencional. Busca-se através desse indicador obter uma medida do bem-estar econômico gerado pela atividade de pesquisa e não de realizar uma análise custo-benefício.

\section{Recorte temporal}

Existe um hiato temporal entre a atividade de pesquisa e os impactos econômicos. Para enfrentar esse desafio metodológico existem dois tipos de avaliações ex ante e ex post. A primeira tem a vantagem de servir de auxílio à decisão porém carece de precisão pois os desdobramentos da inovação são incertos e a segunda é mais precisa por se apoiar em eventos observáveis porém é de menor efetividade porque chega muito tempo depois dos eventos. A avaliação do BETA é ex post, ou seja, pressupõe programas de pesquisa concluídos que já tenham gerado desdobramentos econômicos em seus participantes. Entretanto, esse enfoque possibilita que impactos antecipados que se apóiem em atividades correntes ou investimentos em curso possam ser contabilizados. No Procap 1000, o horizonte de execução do programa foi de 1986 a 1992. A avaliação foi realizada em 1997. Até 1997 os impactos foram constatados. Em seguida, os impactos estimados foram contabilizados até o horizonte temporal de 2006, tomando-se como base atividades já em curso ou investimentos e curso de implantação. Esse limite decorre do horizonte temporal dos impactos que foi limitado a no máximo sete anos. 